\title{
Serological Evidence of Brucellosis in Goats in Kaduna North Senatorial District of Kaduna State, Nigeria
}

\author{
B. Y. Kaltungo, ${ }^{1}$ S. N. A. Saidu, ${ }^{2}$ A. K. B. Sackey, ${ }^{2}$ and H. M. Kazeem ${ }^{3}$ \\ ${ }^{1}$ Veterinary Teaching Hospital, Ahmadu Bello University, Zaria, Nigeria \\ ${ }^{2}$ Department of Veterinary Medicine, Ahmadu Bello University, Zaria, Nigeria \\ ${ }^{3}$ Department of Veterinary Microbiology, Ahmadu Bello University, Zaria, Nigeria
}

Correspondence should be addressed to B. Y. Kaltungo; docbilki@yahoo.com

Received 28 March 2013; Accepted 17 April 2013

Academic Editors: M. Benko and M. Watarai

Copyright (C) 2013 B. Y. Kaltungo et al. This is an open access article distributed under the Creative Commons Attribution License, which permits unrestricted use, distribution, and reproduction in any medium, provided the original work is properly cited.

\begin{abstract}
A cross-sectional study was carried out to determine the current status of Brucella antibodies in goats in Kaduna North Senatorial District of Kaduna State, Nigeria. A total of 442 serum samples (31 bucks and 411 does) were screened using Rose Bengal plate test (RBPT), serum agglutination test with ethylene diaminetetraacetic acid (SAT-EDTA), and lateral flow assay (LFA). Results. The prevalence of Brucella antibodies was found to be $25.8 \%, 11.1 \%$, and $2.5 \%$ using RBPT, SAT-EDTA, and LFA, respectively. The prevalence in bucks was $32.3 \%, 3.2 \%$, and $0.0 \%$ and $17.5 \%, 12.4 \%$, and $3.9 \%$ in does using RBPT, SAT-EDTA, and LFA, respectively. The prevalence rates for goats less than one year of age using the tests were $1.5 \%, 0.0 \%$, and $0.0 \%$. While for those within the age bracket of one to three years, the rates were $19.4 \%, 10.5 \%$, and $3.5 \%$, respectively. The corresponding values for goats above 3 years of age were $34.2 \%, 15.2 \%$, and $1.8 \%$, respectively. The prevalence of brucellosis in goats in the study area is high which poses a threat to the development of the livestock industry and is of important zoonotic implications in Nigeria.
\end{abstract}

\section{Introduction}

Brucellosis is a contagious bacterial infection primarily of livestock [1]. The incidence of the disease in humans is thus closely tied to the prevalence of infection in sheep, goats, and cattle, and to practices that allow exposure of humans to potentially infected animals or their products. Human-to-human transmission of the disease is rare, but the possibility of human-to-human transmission of the organism through bone marrow transplantation, blood transfusion, transmammary route, and sexual intercourse has also been documented $[2,3]$. The World Health Organization (WHO) considers brucellosis to be a neglected zoonosis because, despite its widespread distribution and effects on multiple species, it is not prioritized by national and international health systems [4]. The species of Brucella which infect livestock and their primary hosts are B. melitensis (sheep and goats), B. abortus (cattle), B. suis (pigs), and B. ovis (sheep) $[5,6]$. Brucellosis is well known for its effects on the decrease in productivity of infected livestock by causing abortions, reducing fertility, and decreasing milk yield, resulting in substantial economic losses $[7,8]$.

Diverse serological prevalence ranging between $0.20 \%$ and $79.70 \%$, has been reported in various parts of Nigeria [9]. The infection has further been reported in various animal species in Nigeria [10-16]. This indicates the importance of the disease in Nigeria.

The socioeconomic and cultural relationship between these animals and man, especially children and women, and the fear of spread of brucellosis among these animals and people in the study area, should these animals be harboring the disease cannot be overemphasized. Goats are a major source of animal-based protein, especially in the rural Nigeria. Furthermore, goat's milk and cheese are fast gaining acceptance worldwide because of some of its advantages over cow's milk.

Unconfirmed cases of abortion and stillbirth among others in small ruminants are continuously being handled 
by farmers and animal health workers which apparently may have been caused by members of the Brucella species. These and many other factors pose a risk of infection to humans and they call for attention. It is, therefore, imperative to evaluate the status of brucellosis in those species of animals with a view to advising the government and stakeholders of small ruminant production on the possible risks posed by the disease to health.

There is paucity of information on the current status of the disease in goats in Kaduna North Senatorial District of Kaduna State, Nigeria. This study, therefore, was aimed at determining the current status of brucellosis in goat in four Local Government Areas of Kaduna North Senatorial District of Kaduna State, Nigeria.

\section{Materials and Methods}

2.1. Study Area. The study was conducted in the Kaduna North Senatorial District of Kaduna State is Nigeria (Figure 1). Kaduna State, located in the Northwest Geopolitical Zone of Nigeria. It lies between latitudes $6^{\circ}$ and $11^{\circ}$ North and longitude $7^{\circ}$ and $44^{\circ}$ East and is 608 meters above sea level. It has distinct wet and dry seasons and is within the Northern Guinea Savannah zone and part of the Sahel Savannah zone of Nigeria. The state shares geographical boundaries with Katsina and Zamfara States to the North, Plateau and Bauchi States to the East, Nasarawa State and the Federal Capital Territory to the South, Niger State to the West, and Kano State to the Northeast. Kaduna State occupies about $48,473.25$ sq.km, with a human population of over 6,066,562 people according to the census figures of 2006 [17].

Four out of the seven LGAs in Kaduna North Senatorial District of Kaduna State were selected using simple random sampling without replacement. They include, Ikara, Makarfi, Sabon Gari, and Soba Local Government Areas (LGAs). The location of the flock, animal breed, age, and sex of each animal sampled were recorded. A total of 442 goats were sampled for the purpose of this study, out of which 31 were bucks and 411 were does.

2.2. Study Animals. Pastoral and village level goats were used in this study. The method of flock selection was by random selection and farmers' consent. There was no record of vaccination against brucellosis in any animal species in the area for over twenty years.

\subsection{Study Design, Collection, and Handling of Blood Samples.} The study was carried out between April and May, 2012. Approximately $5 \mathrm{~mL}$ of blood was obtained via a jugular venipuncture of apparently healthy goats of all ages, using a $10 \mathrm{~mL}$ syringe with $21 \mathrm{G}$ needle. The blood samples were then transferred into a well-labeled $10 \mathrm{~mL}$ plain blood-collecting tubes and placed in a slanting position under shade to allow it to clot. The samples were then transported to the laboratory in leak proof ice-packed containers, where they were further centrifuged at $1000 \mathrm{~g}$ for 5 minutes to allow proper separation of serum from the clotted blood. The serum was then decanted into $5 \mathrm{~mL}$ plastic tubes which were properly labelled as for those of the corresponding tubes, after which they were stored in the freezer at $-20^{\circ} \mathrm{C}$ until used.

2.4. Serological Tests. Serum samples were tested for Brucella spp. antibodies by Rose Bengal plate test (RBPT) as described by [18], serum agglutination test with ethylenediaminetetraacetic acid (SAT-EDTA) as described by [19], and lateral flow assay (LFA) according to the manufacturer's instructions. The antigens for the SAT-EDTA and RBPT were obtained from Onderstepoort Biological Products Ltd., South Africa, while the test kit for the LFA was obtained from Bionote INC., Seogu-dong, Hwaseongi-si, Gyeonggido, Republic of Korea.

2.5. Rose Bengal Plate Test. Briefly, $30 \mu \mathrm{L}$ of antigen was placed on a white ceramic tile, and the same volume of $30 \mu \mathrm{L}$ test serum was placed beside the antigen. The two were mixed thoroughly using sterile applicator stick and rocked gently for 4 minutes and observed for agglutination. The formation of distinct pink granules (agglutination) was recorded as positive, while the absence of agglutination was recorded as negative.

2.6. Serum Agglutination Test with Ethylenediaminetetraacetic Acid. Phenol saline with EDTA buffer solution, containing $5 \mathrm{~g}$ phenol crystals, $8.5 \mathrm{~g}$ sodium chloride, and $1.8612 \mathrm{~g}$ disodium EDTA and dissolved in $100 \mathrm{~mL}$ of warm distill water was prepared. A 1:10 dilution of the concentrated SAT antigen with the prepared buffer with a pinch of $0.02 \%$ Safranin O (to provide contrast to the agglutination reaction) was made for each day's work. A 96-well rectangular microtitre plate was set up on the work table. Labeled serum vials were placed on the work table according to positions of the wells, already labeled $\mathrm{A}-\mathrm{H}$ and a corresponding vertical numbering of the wells. A representative entry of the sample details was made in the laboratory record book. Positive and negative were assigned to row "A," while rows $\mathrm{B}-\mathrm{H}$ were designated to the test sera. Using automatic micropipette, $40 \mu \mathrm{L}$ of the buffer solution was measured out into the first well and $25 \mu \mathrm{L}$ into each of the remaining microtitre wells. This was followed by the addition of $10 \mu \mathrm{L}$ of test serum into the first microtitre well using a fresh disposable pipette plastic tip for each test, which was later discarded. A twofold serial dilution was done by transferring $25 \mu \mathrm{L}$ aliquot from the first well up to the fifth well. $25 \mu \mathrm{L}$ of the aliquot was discarded after the last well. Contents of the working dilution of the SAT antigen were mixed gently and $25 \mu \mathrm{L}$ added to each well. Finally, the contents in the microtitre plate were mixed by gently tapping the edges of the plate for 20 seconds. The microtitre plates were covered to prevent evaporation of the contents in the wells and incubated for 20 hours at $37^{\circ} \mathrm{C}$ in an incubator.

2.7. Lateral Flow Assay. $20 \mu \mathrm{L}$ of thawed serum was placed into the sample hole of the test device, followed by the addition of 4 drops of the provided diluent. Test results were read after 20 minutes by visual inspection for staining of the test and control lines. Tests were scored negative when 


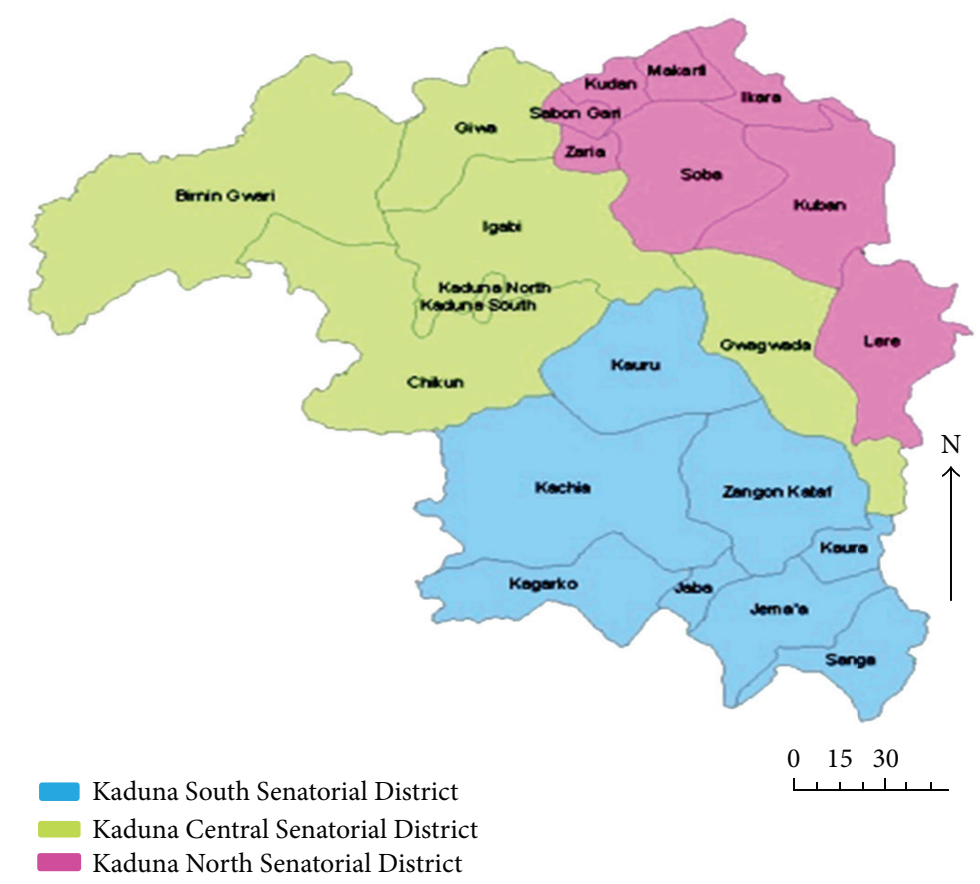

FIGURE 1: Illustrated map of Kaduna State showing the Senatorial Districts. Source: http://www.ncocusa.com/constituencies_kaduna.html.

TABLE 1: Distribution of brucellosis seroprevalence in goats in four Local Government Areas in Kaduna North Senatorial District of Kaduna State, Nigeria.

\begin{tabular}{lcccc}
\hline LGA & $\begin{array}{c}\text { Number } \\
\text { of samples }\end{array}$ & RBPT (\%) & $\begin{array}{c}\text { Positive } \\
\text { SAT-EDTA (\%) }\end{array}$ & LFA (\%) \\
\hline Ikara & 83 & $22(26.5)$ & $12(14.5)$ & $4(4.8)$ \\
Makarfi & 193 & $55(28.5)$ & $13(6.7)$ & $3(1.6)$ \\
Sabon & 56 & $16(28.6)$ & $2(3.6)$ & $0(0.0)$ \\
Gari & 110 & $21(19.1)$ & $22(20.0)$ & $4(3.6)$ \\
Soba & 442 & $114(25.8)$ & $49(11.1)$ & $11(2.5)$ \\
\hline Total & &
\end{tabular}

RBPT: Rose Bengal plate test.

SAT-EDTA: serum agglutination test with ethylene diaminotetra acetic acid. LFA: lateral flow assay.

LGA: Local Government Area.

staining was observed only on the control line, and scored positive when staining was observed on both the test line and control lines.

2.8. Statistical Analysis. Data obtained were subjected to statistical analysis using Chi square $\left(\mathrm{chi}^{2}\right)$ test [20]. Values of $P<0.05$ were considered significant.

\section{Results}

Among the 442 goats sampled for the purpose of this study $114(25.8 \%), 49$ (11.1\%), and 11 (2.5\%) were positive for RBPT, SAT-EDTA, and LFA, respectively (Table 1).

Goats sampled from Sabon Gari LGA had the highest RBPT positive results of 16 (28.6\%), while goats in Soba LGA had the lowest seroprevalence of 21 (19.1\%). Furthermore, the goats in Soba LGA had the highest seroprevalence of $22(20.0 \%)$ when measured with SAT-EDTA, while those in Sabon Gari LGA had the lowest value of 2 (3.6\%). With respect to LFA, the highest seroprevalence of $4(4.8 \%)$ was recorded in Ikara LGA, while Sabon Gari LGA had no positive cases.

Statistical analysis indicated that there was statistical significance in the detection of Brucella antibodies using the three serological tests, $P$ value $<0.0001, \chi^{2}=107.7$, and $\mathrm{df}=2$.

3.1. Seroprevalence Rates per Sex. The number of goats sampled by sex and their seroprevalence rates for brucellosis using RBPT, SAT-EDTA, and LFA are presented in Table 2. Thirty-one male and 411 female goats were sampled. Out of the 31 male goats tested, seroprevalence of 10 (32.3\%), 1 $(3.2 \%)$, and $0(0.0 \%)$ was recorded when tested with RBPT, SAT-EDTA, and LFA, respectively (Table 2). The highest prevalence of 4 (44.4\%) was recorded in Sabon Gari LGAs; none was positive in Soba LGA using RBPT. Similarly, when measured with SAT-EDTA, prevalence of 1 (9.1\%) was recorded in Makarfi LGA, while all the other LGAs sampled had no positive cases for Brucella antibodies. Similarly, for the LFA, all the LGAs sampled recorded zero seroprevalence for Brucella antibodies.

Four hundred and eleven females were tested, and seroprevalence of $72(17.5 \%), 51(12.4 \%)$, and $16(4.0 \%)$ was recorded based on RBPT, SAT-EDTA, and LFA, respectively. The highest seroprevalence of $18(23.1 \%)$ and a corresponding lowest value of 9 (19.2\%) were recorded in Ikara and Sabon Gari LGAs, respectively, using RBPT. With respect to SATEDTA, the highest seroprevalence of 23 (22.1\%) was recorded 
TAble 2: Prevalence of Brucellosis in male and female goats in Kaduna North Senatorial District of Kaduna State, Nigeria.

\begin{tabular}{|c|c|c|c|c|c|c|c|c|}
\hline \multirow{3}{*}{ LGA } & \multicolumn{8}{|c|}{ Sex } \\
\hline & \multirow{2}{*}{ Tested } & \multicolumn{2}{|c|}{$\begin{array}{l}\text { Male } \\
\text { Positive (\%) }\end{array}$} & \multicolumn{4}{|c|}{$\begin{array}{l}\text { Female } \\
\text { Positive (\%) }\end{array}$} & \\
\hline & & RBPT & SAT-EDTA & LFA & & RBPT & SAT-EDTA & LFA \\
\hline Ikara & 5 & $2(40.0)$ & $0(0.0)$ & $0(0.0)$ & 78 & $18(23.1)$ & $13(17.0)$ & $4(5.1)$ \\
\hline Makarfi & 11 & $4(36.4)$ & $1(9.1)$ & $0(0.0)$ & 182 & $51(20.0)$ & $13(7.1)$ & $3(1.7)$ \\
\hline Sabon Gari & 9 & $4(44.4)$ & $0(0.0)$ & $0(0.0)$ & 47 & $9(19.2)$ & $2(4.3)$ & $3(6.4)$ \\
\hline Soba & 6 & $0(0.0)$ & $0(0.0)$ & $0(0.0)$ & 104 & $21(20.2)$ & $23(22.1)$ & $5(4.8)$ \\
\hline Total & 31 & $10(32.3)$ & $1(3.2)$ & $0(0.0)$ & 411 & $72(17.5)$ & $51(12.4)$ & $16(4.0)$ \\
\hline
\end{tabular}

RBPT: Rose Bengal plate test.

SAT-EDTA: serum agglutination test with ethylene diaminotetra acetic acid.

LFA: lateral flow assay.

LGA: Local Government Area.

TABLE 3: Prevalence of Brucellosis in goats per different age groups in Northern part of Kaduna State.

\begin{tabular}{|c|c|c|c|c|c|c|c|c|c|c|c|c|}
\hline \multirow{4}{*}{ LGA } & \multicolumn{12}{|c|}{ Age range (yrs) } \\
\hline & \multirow{3}{*}{ Tested } & \multicolumn{3}{|c|}{$<1$} & \multicolumn{4}{|c|}{$1-3$} & \multicolumn{4}{|c|}{$>3$} \\
\hline & & \multicolumn{3}{|c|}{ Positive (\%) } & \multirow{2}{*}{ Tested } & \multicolumn{3}{|c|}{ Positive (\%) } & \multirow{2}{*}{ Tested } & \multicolumn{3}{|c|}{ Positive (\%) } \\
\hline & & $\mathrm{RBPT}$ & SAT-EDTA & LFA & & RBPT & SAT-EDTA & LFA & & RBPT & SAT-EDTA & LFA \\
\hline Ikara & 2 & $0(0.0)$ & $0(0.0)$ & $0(0.0)$ & 44 & $6(13.6)$ & $5(11.4)$ & $3(7.0)$ & 37 & $14(37.8)$ & $8(22.0)$ & $1(2.7)$ \\
\hline Makarfi & 0 & $0(0.0)$ & $0(0.0)$ & $0(0.0)$ & 95 & $22(21.2)$ & $6(6.3)$ & $1(1.1)$ & 98 & $33(34.0)$ & $8(8.2)$ & $2(2.0)$ \\
\hline Sabon Gari & 5 & $3(60.0)$ & $0(0.0)$ & $0(0.0)$ & 36 & $8(22.2)$ & $1(2.8)$ & $0(0.0)$ & 15 & $2(13.3)$ & $1(7.0)$ & $0(0.0)$ \\
\hline Soba & 13 & $0(0.0)$ & $0(0.0)$ & $0(0.0)$ & 83 & $14(17.0)$ & $15(18.1)$ & $5(6.0)$ & 14 & $7(50.0)$ & $8(57.1)$ & $0(0.0)$ \\
\hline Total & 20 & $3(15.0)$ & $0(0.0)$ & $0(0.0)$ & 258 & $50(19.4)$ & $27(10.5)$ & $9(3.5)$ & 164 & $56(34.2)$ & $25(15.2)$ & $3(1.8)$ \\
\hline
\end{tabular}

RBPT: Rose Bengal plate test.

SAT-EDTA: serum agglutination test with ethylene diaminotetra acetic acid.

LFA: lateral flow assay.

LGA: Local Government Area.

in Soba LGA, and the lowest value of $2(4.3 \%)$ was recorded in Sabon Gari LGA. Similarly, using the LFA, the highest seroprevalence of $3(6.4 \%)$ was recorded in Sabon Gari LGA and the lowest value of $3(1.7 \%)$ was recorded in Makarfi LGA.

There was no statistical significant difference in seroprevalence rates of Brucella antibodies between the male and female animals, $P=0.6168$.

3.2. Seroprevalence Rate per Age. A total of 20 goats of less than one year of age were tested. In this category, only animals from Sabon Gari LGA recorded a seroprevalence of 3 (60\%) when tested with RBPT; all the LGAs recorded zero seroprevalence. Zero seroprevalence was also recorded for all the LGAs using SAT-EDTA and LFA, respectively.

Out of the 258 goats tested within the age bracket of 1-3 years, prevalence of $50(19.4 \%), 27(10.5 \%)$, and $9(3.5 \%)$ was recorded based on RBPT, SAT-EDTA, and LFA, respectively. Sabo Gari LGA recorded the highest seroprevalence of 8 (22.2\%) in terms of RBPT, while Ikara LGA recorded the lowest value of 6 (13.6\%) (Table 3). Similarly, the seropositivity, when tested with SAT-EDTA, was the highest in goats from Soba LGA with a seroprevalence of $15(18.1 \%)$, and lowest value of $1(2.8 \%)$ was recorded from goats in Sabon Gari LGA. Furthermore, Soba LGAs recorded the highest seroprevalence rate in terms of the LFA with the value of 5
(6.0), while zero prevalence was recorded from goats in Sabon Gari LGA.

Similarly, 164 goats above the age of three years were tested and seroprevalence rates of 56 (34.2\%), 25 (15.2\%), and $3(1.8 \%)$ were recorded, based on RBPT, SAT-EDTA, and LFA, respectively. Soba LGA recorded the highest seroprevalence of $7(50.0 \%)$ in terms of RBPT, while Sabon Gari LGA recorded the lowest value of 2 (13.3\%) (Table 3). Similarly, the seropositivity with regards to SAT-EDTA was the highest in Soba LGA with the seroprevalence of 8 (57.1\%), and the lowest value of 1 (7.0\%) was recorded in goats from Sabon Gari LGA. Furthermore, Ikara LGA recorded the highest seroprevalence of $1(2.7 \%)$ when tested with LFA, while the zero seroprevalence was obtained in Sabon Gari and Soba LGAs, respectively.

Statistical analysis indicated that there was no significant difference in prevalence rates of brucellosis between goats of all age groups tested $\left(P=0.4427, \chi^{2}=1.630\right.$, and $\left.\mathrm{df}=2\right)$.

\section{Discussion}

The present study has established the serological evidence of brucellosis in goats in Kaduna North Senatorial District of Kaduna State. The overall prevalence of $2.5 \%$ based on the confirmatory test (LFA) in this work is comparable to that reported by Brisibe et al. [21], where a prevalence of $2.8 \%$ was 
obtained in Northern Nigeria. However, a higher prevalence of $9.0 \%, 5.88 \%$, and $4.75 \%$ was reported in goats by Falade and Shonekan [13], Ogundipe et al. [22], and Shehu et al. [23], respectively. Similarly, an alarming prevalence of $45.75 \%$ was reported by Ojo et al. [24] in a goat flock in Abeokuta in western Nigeria. Despite the wide distribution of the seroprevalence throughout the LGAs sampled, there are some differences between the Local Government Areas which may be attributed to the migratory habit of the Fulani pastoralists. This observation may account for infection in small ruminants since they are allowed to mix freely with cattles, and it was reported that there is an increase in seroprevalence of brucellosis among the Fulani pastoralists' cattles [25]. The difference in the seroprevalence obtained by different workers may be due to sensitivities and specificities of the different diagnostic methods used among the researchers.

The present study also shows that more animals were seropositive with RBPT and SAT-EDTA as compared with the LFA. The high seroprevalence rate from the RBPT may be attributed to the relatively low specificity and very high sensitivity of the test. Apparently, it could also as a result of reaction to other SLPS Brucella species, especially $B$. abortus since. This is because goats in the study area are herded or kept together with cattle. It could also be due to other Gram-negative bacteria like Vibrio cholerae O1, Escherichia coli O: 157, some strains of Escherichia hermannii and Stenotrophomonas maltophilia, Salmonella group N (O: 30), and Yersinia enterocolitica O: 9 which has LPS Ochains similar to those of brucellae. These organisms have agglutinins capable of reacting with Brucella antigens, thus giving false positive reactions. Despite these limitations, the RBPT may be used as a screening test to ascertain exposure of animals to infection due to Brucella species.

The seroprevalence rate was lower with the SAT-EDTA, and this finding may be attributed to the increase in specificity of this test. The result agrees with the finding of Bertu et al. [26] where prevalence of 9.3\% and 5.2\% with RBPT and SAT was obtained, respectively. The SAT-EDTA was particularly more specific because of the addition of ethylenediaminetetraacetic acid (EDTA) which increases the specificity of the test by eliminating nonspecific agglutination reactions, apparently by preventing binding between Brucella cell surface components and the Fc portion of IgM [27].

The least seroprevalence rate recorded with the LFA was indicative of its very high specificity since it only detects antibodies due to B. melitensis. Due to the high sensitivity, specificity, and simplicity of the test and especially that the test does not involve any expertise nor refrigeration, it is recommended that this assay should be used for serological survey of Brucellosis I in Nigeria, particularly in the rural areas.

From the study, female animals were more seropositive than their male counterparts. This could be due to the fact that more females were available for sampling as they are kept in the flock for a longer period for the purpose of breeding. This is in agreement with the work of Mohammed et al. [28] where it was reported that female animals were more seropositive than males. Generally, goat farmers keep fewer males because of their aggressive nature and mainly for breeding the females. Furthermore, the higher prevalence may be because female goats are more susceptible than males as reported by Keppie et al. [29].

The animals within the age of 1-3 years of both sexes had the highest seroprevalence rate. This finding is in agreement with the results obtained by Mohammed et al. [28], Aulakh et al. [30], and Abubakar et al. [31], who reported that the incidence is higher in sexually mature animals. Furthermore, in this study, more animals within this age bracket were sampled. The animals within this age range are actively involved in breeding. Therefore, the presence of brucellosis in them may result in serious economic loss in terms of reproductive wastages like abortion, still-birth, infertility, sterility, and reduced milk production. It also means that they are capable of spreading the infection since they mix among themselves from different flocks. It is also important to note that animals in this age bracket are more often sold out for slaughter and may pose serious risk to humans as a source of infection.

Animals of less than 1 year of age that were seropositive may have been exposed through suckling of their infected dams. They may also have been infected through contaminated pasture or water at grazing and watering points. Infection of goats of this age is an evidence of their potential to develop the disease and consequently spread it to others.

As for goats that were over 3 years old, the high prevalence recorded in them was because the animals have acquired the infection much earlier in life.

\section{Conclusion}

The present study has shown that brucellosis exists in goats in the study area. It has also indicated that RBPT is an important screening test for brucellosis and that the LFA is a reliable test for identification of $B$. melitensis. Furthermore, the female goats were found to be more affected than their male counterparts, and goats within the age of 1-3 years are more affected. In view of the importance of brucellosis to the livestock industry and its zoonotic importance, government should institute stringent control measures and possible eradication strategies of the disease.

\section{Acknowledgments}

The authors wish to express their appreciation to the farmers, veterinary personnel from the LGAs involved in this study, Head of Department, and laboratory staff, Department of Public Health and Preventive Medicine, Faculty of Veterinary Medicine, Ahmadu Bello University, Zaria, Nigeria.

\section{References}

[1] R. Munir, M. Afzal, M. Hussain, S. M. S. Naqvi, and A. Khanum, "Outer membrane proteins of Brucella abortus vaccinal and field strains and their immune response in buffaloes," Pakistan Veterinary Journal, vol. 30, no. 2, pp. 110-114, 2010.

[2] M. J. A. Carrera, A. M. L. Rodriguez, A. Sapiña, A. L. Lafuente, and A. R. Sacristán, "Probable transmission of brucellosis by 
breast milk," Journal of Tropical Pediatrics, vol. 52, pp. 380-381, 2006.

[3] Y. Kato, G. Masuda, I. Itoda, A. Imamura, A. Ajisawa, and M. Negishi, "Brucellosis in a returned traveler and his wife: probable person-to-person transmission of Brucella melitensis," Journal of Travel Medicine, vol. 14, no. 5, pp. 343-345, 2007.

[4] World Health Organization (WHO), "The control of neglected zoonotic diseases," Report of the first meeting on the control of neglected zoonotic diseases, WHO and Department for International Development-Animal Health Programme (DFID-AHP), with the participation of FAO and OIE 20-21, 2005.

[5] R. Crawford, "Epidemiology and surveillance," in Animal Brucellosis, K. H. Nielsen and J. R. Duncan, Eds., pp. 131-151, CRC Press, Boca Raton, Fla, USA, 1990.

[6] M. Meyer, "Evolutionary development and taxonomy of the genus Brucella," in Advances in Brucellosis Research, L. G. Adams, Ed., pp. 12-35, Texas A\&M University Press, 1990.

[7] P. Nicoletti, “The epidemiology of bovine brucellosis," Advances in Veterinary Science and Comparative Medicine, vol. 24, pp. 6998, 1980.

[8] M. Corbel, "Brucellosis," in Fertility and Infertility in Veterinary Practice, J. Laing, Ed., pp. 190-221, Bailliere Tindall, ELBS, 4th edition, 1988.

[9] S. I. B. Cadmus, I. F. Ijagbone, H. E. Oputa, H. K. Adesokan, and J. A. Stack, "Serological survey of brucellosis in livestock animals and workers in Ibadan, Nigeria," African Journal of Biomedical Research, vol. 9, pp. 163-168, 2006.

[10] G. O. Esuruoso and D. H. Hill, "Sero-epidemiological survey of bovine brucellosis in dairy herds in the Western States of Nigeria," Nigerian Agricultural Journal, vol. 8, pp. 147-154, 1971.

[11] G. O. Esuruoso, "Bovine brucellosis in Nigeria," Veterinary Record, vol. 95, no. 3, pp. 54-58, 1974.

[12] S. Falade, "Brucella agglutinating antibodies in the sera of persons dwelling in Ibadan and the surrounding districts," Journal of Nigerian Veterinary Medical Association, vol. 3, pp. 21-23, 1974.

[13] S. Falade and O. A. Shonekan, "A serological survey of Brucella abortus infection in Nigerian sheep," Nigerian Veterinary Journal, vol. 2, pp. 50-52, 1981.

[14] S. Falade, M. O. Ojo, and K. C. Sellers, "A serological survey of caprine brucellosis in Nigeria," Bulletin of Epizootic Diseases of Africa, vol. 22, no. 4, pp. 335-339, 1974.

[15] A. E. J. Okoh, I. Alexiev, and D. E. Agbonlahor, "Brucellosis in dogs in Kano, Nigeria," Tropical Animal Health and Production, vol. 10, no. 4, pp. 219-220, 1978.

[16] N. B. Adamu and I. Ajogi, "Serological investigation of camels (Camelus dromadarius) slaughtered at Kano Municipal Abattoir for evidence of brucellosis," Tropical Veterinarian, vol. 18, pp. 45-48, 1995.

[17] Kaduna state Government (KDSG), "Kaduna state acheivemements," in Data on Estimated Annual Animal Population and Fish Production Investment Opportunities in Kaduna State 2007, pp. 16-18, 2008.

[18] G. G. Alton, L. M. Jones, and D. E. Pietz, Laboratory Techniques in Brucellosis, World Health Organization Monograph Series No. 55, World Health Organization, Geneva, Switzerland, 2nd edition, 1975.

[19] S. L. Brown, G. C. Klein, F. T. McKinney, and W. L. Jones, "Safranin O-stained antigen microagglutination test for detection of Brucella antibodies," Journal of Clinical Microbiology, vol. 13, no. 2, pp. 398-400, 1981.
[20] G. W. Snedecor and W. G. Cochran, Statistical Methods, IOWA State University Press, Ames, Iowa, USA, 7th edition, 1980.

[21] F. Brisibe, D. R. Nawathe, and C. J. Bot, "Serological prevalence of brucellosis in sheep, goats and human beings in Maiduguri Metropolis," Tropical Veterinarian, vol. 11, pp. 27-33, 1993.

[22] G. A. T. Ogundipe, H. N. Hwaichi, and F. O. Ayanwal, "A serological survey for the prevalence of Brucella antibodies in slaughter goats in Ibadan," Bulletin of Animal Health and Production in Africa, vol. 42, pp. 14-118, 1994.

[23] L. M. Shehu, H. Yusuf, A. C. Kudi, and D. U. Kalla, "Seroprevalence of brucellosis in ruminants in Bauchi and environs," Nigerian Veterinary Journal, vol. 20, no. 1, pp. 67-74, 1999.

[24] O. E. Ojo, M. A. Oyekunle, S. O. Omotainse, R. A. Ocholi, A. O. Ogunleye, and W. J. Bertu, "Serological evidence of brucellosis in a goat flock with recurrent abortion in Abeokuta, Nigeria," Tropical Veterinarian, vol. 25, no. 1, pp. 26-33, 2007.

[25] R. A. Ocholi, J. K. P. Kwaga, I. Ajogi, and J. O. O. Bale, "Phenotypic characterization of Brucella strains isolated from livestock in Nigeria," Veterinary Microbiology, vol. 103, no. 1-2, pp. 47-53, 2004.

[26] W. J. Bertu, I. Ajogi, J. O. O. Bale, J. K. P. Kwaga, and R. A. Ocholi, "Sero-epidemiology of brucellosis in small ruminants in Plateau State, Nigeria," African Journal of Microbiology Research, vol. 4, no. 19, pp. 1935-1938, 2010.

[27] F. P. Poiester, K. Nielsen, L. E. Samartino, and W. L. Yu, "Diagnosis of brucellosis," Open Veterinary Science Journal, vol. 4, p. $46,2010$.

[28] F. U. Mohammed, S. Ibrahim, I. Ajogi, and J. O. O. Bale, "Prevalence of bovine brucellosis and risk factors assessment in cattle herd in Jigawa State," ISRN Veterinary Science, vol. 2011, Article ID 132897, 4 pages, 2011.

[29] J. Keppie, A. E. Williams, K. Witt, and H. Smith, "The role of erythritol in the tissue localization of the brucellae," The British Journal of Experimental Pathology, vol. 46, no. 1, pp. 104-108, 1965.

[30] H. K. Aulakh, P. K. Patil, S. Sharma, H. Kumar, V. Mahajan, and K. S. Sandhu, "A study on the epidemiology of bovine brucellosis in Punjab (India) using milk-ELISA," Acta Veterinaria Brno, vol. 77, no. 3, pp. 393-399, 2008.

[31] M. Abubakar, M. J. Arshed, M. Hussain, Ehtisham-Ul-Haq, and Q. Ali, "Serological evidence of Brucella abortus prevalence in Punjab Province, Pakistan-a cross-sectional study," Transboundary and Emerging Diseases, vol. 57, no. 6, pp. 443-447, 2010. 

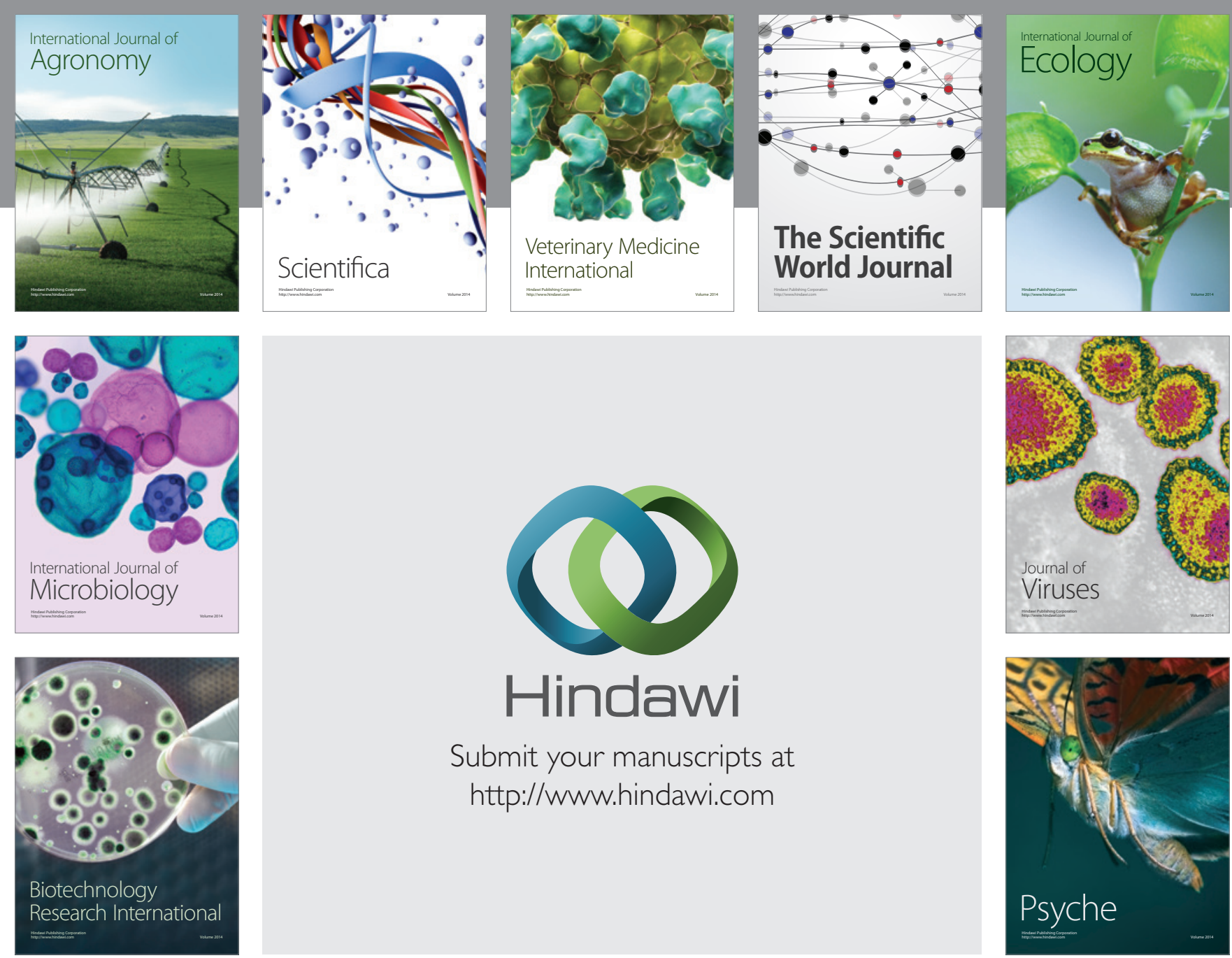

Submit your manuscripts at http://www.hindawi.com
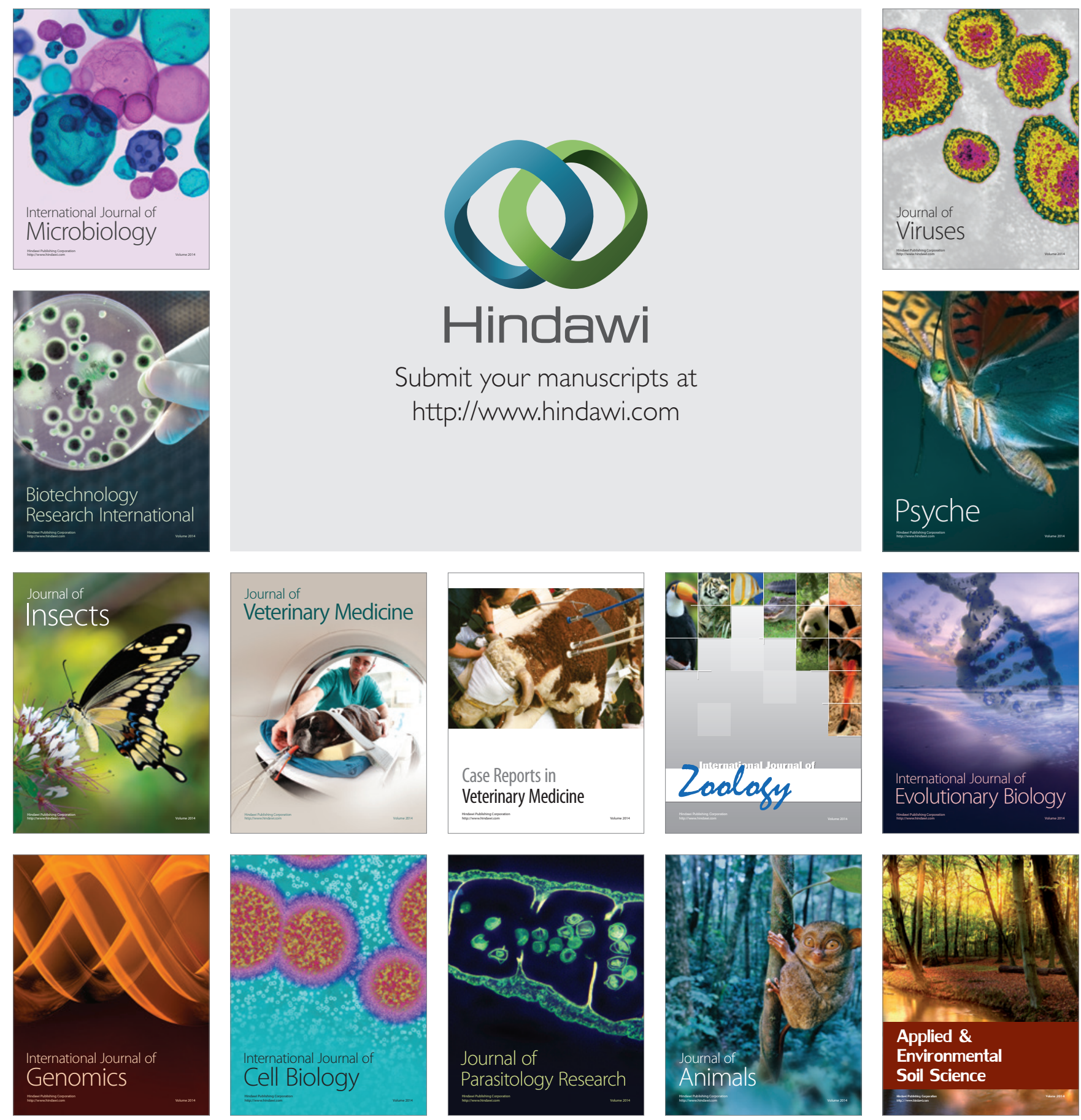